\title{
Management of venous thromboembolism with non-vitamin K oral anticoagulants: A review for nurse practitioners and pharmacists
}

Michelle Schmerge, DNP, ANP-BC, MSN, RN (Director of Post Acute Care)', Sally Earl, PharmD, BCPS (Clinical Assistant Professor of Pharmacy Practice) ${ }^{2,3}$, \& Carol Kline, RN (Coumadin Nurse) ${ }^{4}$

\begin{abstract}
Background and purpose: Venous thromboembolism (VTE), comprising deep-vein thrombosis and pulmonary embolism, is associated with significant morbidity and mortality. Non-vitamin K oral anticoagulants (NOACs), including apixaban, betrixaban, dabigatran, edoxaban, and rivaroxaban, are as effective and safe as vitamin $\mathrm{K}$ antagonists (VKAs) for primary prophylaxis, treatment, and/or secondary prevention of VTE and present significant advantages in convenience of use. This review provides guidance to nurse practitioners (NPs) and pharmacists on NOAC usage for the management of VTE and examines how traditional anticoagulation clinics can adapt to cater to patients on NOACS.
\end{abstract}

Methods: A review of the scientific literature pertaining to treatment guideline recommendations, large randomized clinical trials, and real-world evidence studies related to VTE management was conducted.

Conclusions: With current data suggesting that NOACs may present as better alternatives over VKAs for the management of VTE, comprehensively educating NPs and pharmacists can help incorporate these agents in their clinical practice.

Implications for practice: Repurposing anticoagulation clinics, led by well-informed NPs and pharmacists, will allow effective integration and optimal management of patients with VTE taking NOACS as well as those taking VKAs.

Keywords: Non-vitamin K oral anticoagulants; nurse practitioner; venous thromboembolism; vitamin K antagonists.

Journal of the American Association of Nurse Practitioners 30 (2018) 185-192, ( 2018 American Association of Nurse Practitioners

DOI\# 10.1097/JXX.0000000000000043

\section{Introduction}

Venous thromboembolism (VTE), comprising deep-vein thrombosis (DVT) and pulmonary embolism (PE), is a multifactorial, chronic disease with episodic recurrence. Common risk factors include hospitalization for surgery or acute illness, trauma or fracture, prolonged immobility, active cancer, obesity, and increasing age (Heit, Spencer, \& White, 2016).The annual incidence of VTE events in the United States (US) ranges from 300,000 to 600,000 (Mozaffarian et al., 2016) and is associated with significant

\footnotetext{
${ }^{1}$ Post Acute Care, Novant Health, Charlotte, NC, ${ }^{2}$ Department of Pharmacy Practice, The University of Mississippi, School of Pharmacy, University, MS, ${ }^{3}$ Previously at Cone Health Medical Group HeartCare, Greensboro, NC, ${ }^{4}$ Carolinas HealthCare System, Charlotte, NC

Correspondence: Michelle Schmerge, DNP, ANP-BC, MSN, RN, Novant Health Prosperity Family Physicians, 8310 University Executive Park Drive, Suite 550, Charlotte, NC 28262. Tel: (704) 384-1225; Fax: (704) 3164931; E-mail: mbschmerge@novanthealth.org

Received: 30 October 2017; accepted 14 February 2018
}

morbidity and mortality (Spyropoulos, Preblick, Kwong, Lingohr-Smith, \& Lin, 2015). VTE and its complications are an economic burden, costing the US health care system \$7-10 billion dollars per year (Brahmandam, Abougergi, \& Ochoa Chaar, 2017). Standard therapy for treating VTE includes parenteral anticoagulation with heparin overlapping with an oral vitamin K antagonist (VKA) such as warfarin, followed by a VKA alone. VKAs have also been the cornerstone for long-term prevention of recurrent VTE (Kearon et al., 2012). However, recent evidence suggests that non-vitamin K oral anticoagulants (NOACs), including apixaban, dabigatran, edoxaban, and rivaroxaban, may offer an improved benefitrisk profile than VKAs for patients with VTE (Raschi, Bianchin, Ageno, De Ponti, \& De Ponti, 2016). A new entrant to the NOAC therapeutics class is betrixaban, which was recently approved for VTE prophylaxis in adult patients with acute illness.

Nurse practitioners (NPs) and pharmacists play an important role in the management of patients with VTE by conducting systemic patient risk assessments, managing 
medical therapy, and providing education. Appointing an anticoagulation nurse to assist patients in educational sessions, reminders, and continued feedback can improve VTE thromboprophylaxis to high-risk patients (Goldstein et al., 2016). Establishing a nurse-patient partnership can further promote proper risk assessments as well as clinical guidance on best VTE prevention practices (Lockwood, Kable, \& Hunter, 2017 [Epub ahead of print]). Pharmacist-led services also improve clinical outcomes in the anticoagulation setting. A recent metaanalysis reported the benefits of pharmacist-led anticoagulation management, which significantly decreased total hemorrhage events, minor hemorrhage events, and thrombosis events in patients with indications for warfarin (Hou et al., 2017). Pharmacist-led services have also demonstrated improvements in appropriate dosing as well as patient adherence to therapy (Ashjian, Kurtz, Renner, Yeshe, \& Barnes, 2017).

VTE management initiatives involving NPs or pharmacists can be highly effective and provide significant clinical and economic benefits. This necessitates providing these specialists with the requisite knowledge to assist in clinical decision-making. Notably, in a Pennsylvania cohort study, the number of anticoagulant prescriptions written by NPs more than doubled from $1.5 \%$ in 2007 to $3.4 \%$ in 2011 . The same study also found that only $18.5 \%$ of NPs ordered at least one prescription of dabigatran (the only NOAC available at the time) compared with $44.3 \%$ of primary care physicians (PCPS). The authors opined that although NPs play an important role in the management of chronic diseases, they are slower than PCPs to adopt new drug regimens, likely because of treating patients covered by the more restrictive Medicaid (Marcum, Bellon, Li, Gellad, \& Donohue, 2016).

This review aims to provide guidance to NPs and pharmacists with regard to NOAC vs VKA therapy for managing VTE and also discusses how traditional anticoagulation clinics could be adapted to meet the needs of patients with VTE, irrespective of anticoagulant therapy.

\section{Search strategy}

A literature search was conducted with the EMBASE, Google Scholar, and PubMed databases using the following keywords: anticoagulation, non-vitamin $\mathrm{K}$ oral anticoagulant, management, nurse, nurse practitioner, pharmacist, and/or venous thromboembolism. Inclusion criteria were English-only articles with full text published between 2013 and 2017. Prescribing information of NOAC agents, current treatment guidelines, and references from included publications were used to identify other articles of interest. Only pivotal Phase 3 clinical trials that contributed to agent approval for the primary, secondary, or prophylactic treatment of VTE were included.

An additional literature search was performed for real-world evidence studies with the EMBASE database using the following keywords: venous thromboembolism, deep-vein thrombosis, pulmonary embolism, nonvitamin K oral anticoagulant, real-world evidence, and/or registry. Inclusion criteria were English-only articles with full text published between 2013 and 2017. Review of titles and abstracts eliminated articles that were not specific to VTE management and also helped identify other studies of interest. The final literature search yielded five studies.

\section{Vitamin K antagonist versus NOAC therapy for venous thromboembolism}

Traditionally, anticoagulant therapy for VTE begins with initial parenteral unfractionated heparin, low-molecularweight heparin (LMWH), or fondaparinux for short-term anticoagulation and a VKA for long-term use (Kearon et al., 2012). This dual-drug approach is due to the slow onset of action of VKAs (72-96 hr), requiring a bridging period with rapid-acting heparin injections (eg, Lovenox [enoxaparin]) before transitioning to a VKA alone. For patients with VTE, adjusted-dose VKA can significantly reduce the risk of thrombotic event recurrence by inhibiting vitamin K-dependent clotting factor synthesis (Schein et al., 2016). Challenges associated with VKA use include increased risk of medication-related issues, such as concern with administration and bleeding during the bridging period (Eijgenraam, ten Cate, \& ten Cate-Hoek, 2014) and unpredictable dose response because of drug-drug and drug-food interactions. Maintenance of a stable international normalized ratio (INR) within the therapeutic range also complicates VKA administration despite systematic approaches to routinely monitor INR. In fact, lower time in the target therapeutic range (TTR) is associated with significantly poorer outcomes. Increased health care resources and costs can also result from mismanagement of VKAs, medication noncompliance, and discontinuation (Schein et al., 2016).

NOACs are distinct from VKAs because they bind and inhibit specific clotting factors within the coagulation cascade versus decreasing the production of multiple components of the cascade. They are categorized into two broad classes: (1) direct thrombin inhibitors, such as dabigatran, which bind to the active site of thrombin and inhibit thrombin-dependent conversion of fibrinogen to fibrin and (2) direct factor Xa inhibitors, including apixaban, betrixaban, edoxaban, and rivaroxaban, which bind and inhibit the active site of the upstream coagulation factor $\mathrm{Xa}$ (the clotting factor responsible for activating prothrombin to thrombin). Both classes directly inhibit free and clot-bound fibrin and indirectly inhibit thrombin-induced platelet aggregation (Oktay, 2015; Palladino, Merli, \& Thomson, 2013).

As effective alternatives to VKAs, NOACs improve the benefit-risk profile in the acute setting (Agnelli, Buller, Cohen, Curto, Gallus, Johnson, Masiukiewicz, et al., 2013; Cohen et al., 2016; Einstein-PE Investigators, 2012; Einstein 


\section{Table 1. Pharmacological characteristics of non-vitamin K oral anticoagulants (NOACs)}

\begin{tabular}{lccccc} 
& \multicolumn{4}{c}{ NOAC } \\
\cline { 2 - 6 } Characteristic & Apixaban & Betrixaban & Edoxaban & Rivaroxaban & Dabigatran \\
\hline $\begin{array}{l}\text { Mechanism of } \\
\text { action }\end{array}$ & $\begin{array}{l}\text { Direct factor Xa } \\
\text { inhibitor }\end{array}$ & $\begin{array}{l}\text { Direct factor Xa } \\
\text { inhibitor }\end{array}$ & $\begin{array}{l}\text { Direct factor Xa } \\
\text { inhibitor }\end{array}$ & $\begin{array}{l}\text { Direct factor Xa } \\
\text { inhibitor }\end{array}$ & $\begin{array}{l}\text { Direct thrombin } \\
\text { inhibitor }\end{array}$ \\
\hline $\begin{array}{l}\text { Bioavailability, } \\
\%\end{array}$ & 50 & 34 & 62 & $80-100$ & $3-7$ \\
\hline Half-life (hr) & 12 & $19-27$ & $10-14$ & $5-9^{\text {a }}$ & 12-17 \\
\hline $\begin{array}{l}\text { Renal } \\
\text { elimination, \% }\end{array}$ & 27 & 11 & 50 & 266 & 80 \\
\hline $\begin{array}{l}\text { Drug } \\
\text { interactions }\end{array}$ & $\begin{array}{l}\text { Combined P-glycoprotein } \\
\text { and strong CYP3A4 } \\
\text { inhibitors and inducers }\end{array}$ & $\begin{array}{l}\text { P-glycoprotein } \\
\text { inhibitors }\end{array}$ & $\begin{array}{l}\text { P-glycoprotein } \\
\text { inducers }\end{array}$ & $\begin{array}{l}\text { Combined P-glycoprotein } \\
\text { and strong CYP3A4 } \\
\text { inhibitors and inducers }\end{array}$ & $\begin{array}{l}\text { P-glycoprotein } \\
\text { inhibitors and } \\
\text { inducers }\end{array}$ \\
\hline
\end{tabular}

Note: Data obtained from US Prescribing Information for Eliquis (apixaban), Bevyxxa (betrixaban), Savaysa (edoxaban), Xarelto (rivaroxaban), and Pradaxa (dabigatran). aln healthy subjects aged $20-45$ years.

Investigators, 2010; Hokusai-VTE Investigators, 2013; Schulman et al., 2009, 2014) and have proven efficacious and safe for secondary prevention of VTE (Agnelli, Buller, Cohen, Curto, Gallus, Johnson, Porcari, et al., 2013; Cohen et al., 2016; Einstein Investigators, 2010; Schulman et al., 2013). NOACs have also overcome the limitations of VKA management by offering convenient, fixed, once- or twice-daily dosing regimens for patients, without the need for INR monitoring (Table 1). NOACs have a rapid onset/ offset of action and a peak effect within hours, with predictable pharmacokinetics eliminating the need for routine monitoring (Table 2) (Heidbuchel et al., 2015). NOACs are also beneficial because they have minimal drug-drug interactions, although antifungal, antimicrobial, and antiviral medications can interact with the major metabolic pathways of most NOACs (CYP3A4 and Pglycoprotein) (Lee, 2016).

Since 2008, when NOACs were approved by regulatory agencies in both the European Union (EU) and the US, they have been recommended for a variety of thromboembolic indications. Large, randomized, Phase 3 clinical trials evaluated apixaban, betrixaban, dabigatran, edoxaban, and rivaroxaban versus conventional therapy for the treatment of VTE in the AMPLIFY (NCT00643201), APEX (NCT01583218), RE-COVER I (NCT00291330), RE-MEDY (NCT00329238), RE-SONATE (NCT00558259), Hokusai-VTE (NCT00986154), and EINSTEIN-DVT (NCT00440193)/-PE (NCT00439777) trials, respectively. Data revealed that NOACs were noninferior to LMWH/VKA/placebo for primary prophylaxis, treatment, and secondary prevention of VTE. The risk of major bleeding and/or clinically relevant nonmajor bleeding (CRNM) is also comparable or decreased with NOAC use (Agnelli, Buller, Cohen, Curto, Gallus, Johnson, Masiukiewicz, et al., 2013; Cohen et al.,
2016; Einstein-PE Investigators, 2012; Einstein Investigators, 2010; Hokusai-VTE Investigators, 2013; Schulman et al., 2009, 2014). A recent meta-analysis compared the efficacy and safety of apixaban, dabigatran, edoxaban, and rivaroxaban across the six major Phase 3 clinical trials for initial and long-term VTE treatment and reported no statistically significant differences in the risk of VTE and VTE-related death among them (Cohen et al., 2015). Further, NOAC use reduces the risk of all-cause mortality and intracranial hemorrhage-the most feared complication of VKA usage (Robinson, 2015).

\section{Real-world evidence}

Real-world evidence, although limited, supports data from phase 3 randomized controlled trials. XALIA (NCT01619007), a noninterventional study comparing standard therapy (initial unfractionated heparin, LMWH, or fondaparinux, overlapping with a VKA) with rivaroxaban for long-term and initial anticoagulation for VTE, demonstrated lower rates of major bleeding and recurrent VTE with rivaroxaban (Turpie et al., 2015). The Dresden NOAC registry study (NCT01588119) is currently examining treatment of acute VTE with rivaroxaban. Initial findings revealed that rivaroxaban is effective and has acceptable major bleeding rates in unselected patients in daily care (Keller et al., 2016). Also underway, the Global Anticoagulant Registry in the FIELD-Venous Thromboembolism (GARFIELD-VTE; NCT02155491) is an observational study investigating acute and long-term VTE management among 500 sites across 28 countries (Weitz et al., 2016). PREFER, in VTE (DRKS register, ID number: DRKS00004795), is an ongoing, multicenter, prospective, observational disease study of quality of life and treatment satisfaction of $\sim 3,500$ patients with VTE 
Table 2. Prescribing dosages of non-vitamin K oral anticoagulants (NOACs) for VTE treatment and prevention

\begin{tabular}{|c|c|c|c|c|c|}
\hline \multirow[b]{2}{*}{ Indication } & \multicolumn{5}{|c|}{ NOAC } \\
\hline & Apixaban $^{a}$ & Betrixaban $^{\mathbf{b}}$ & Edoxaban ${ }^{c}$ & Rivaroxaban $^{\text {d }}$ & Dabigatran ${ }^{\mathrm{e}}$ \\
\hline VTE treatment & $\begin{array}{l}\text { - } 10 \text { mg orally BID for } 7 \text { days, } \\
\text { followed by } 5 \text { mg orally BID }\end{array}$ & & $\begin{array}{l}\text { - } 60 \text { mg QD } \\
\text { - For patients with } \mathrm{CrCl} 15-50 \\
\text { ml/min or BW } \leq 60 \mathrm{~kg} \text { : } \\
30 \mathrm{mg} \text { QD }\end{array}$ & $\begin{array}{l}\text { - } 15 \text { mg BID with food for } 21 \\
\text { days, then } \\
\text { - } 20 \text { mg QD with food }\end{array}$ & $\begin{array}{l}\text { For patients with } \mathrm{CrCl}>30 \\
\mathrm{ml} / \mathrm{min}: 150 \mathrm{mg} \text { orally } \mathrm{BID} \\
\text { after 5-10 days of parenteral } \\
\text { anticoagulation }\end{array}$ \\
\hline $\begin{array}{l}\text { Reduction in the risk of VTE } \\
\text { recurrence after initial } \\
\text { therapy }\end{array}$ & - 2.5 mg orally BID & & NA & - 20 mg QD with food & $\begin{array}{l}\text { For patients with } \mathrm{CrCl}>30 \\
\mathrm{ml} / \mathrm{min}: 150 \mathrm{mg} \text { orally BID } \\
\text { after previous treatment }\end{array}$ \\
\hline $\begin{array}{l}\text { VTE prophylaxis after hip or } \\
\text { knee replacement surgery }\end{array}$ & - 2.5 mg orally BID & & NA & $\begin{array}{l}\text { - } 10 \text { mg orally QD with or } \\
\text { without food }\end{array}$ & $\begin{array}{l}\text { For patients with } \mathrm{CrCl}>30 \\
\mathrm{ml} / \mathrm{min}: 110 \mathrm{mg} \text { orally first } \\
\text { day, then } 220 \mathrm{mg} \text { QD }\end{array}$ \\
\hline $\begin{array}{l}\text { VTE prophylaxis in acutely ill, } \\
\text { hospitalized patients }\end{array}$ & & $\begin{array}{l}\text { - Initial dose of } 160 \mathrm{mg} \text {, } \\
\text { followed by } 80 \mathrm{mg} \text { QD at } \\
\text { the same time with food } \\
\text { - Recommended duration is } \\
35-42 \text { days }\end{array}$ & & & \\
\hline
\end{tabular}

Note: Data obtained from US Prescribing Information for Eliquis (apixaban), Bevyxxa (betrixaban), Savaysa (edoxaban), Xarelto (rivaroxaban), and Pradaxa (dabigatran).

Note: $B I D=$ twice a day; $\mathrm{CrCl}=$ creatinine clearance; $D V T=$ deep-vein thrombosis; $N A=$ not applicable; $P E=$ pulmonary embolism; $Q D=$ once a day.

${ }^{a}$ For patients receiving apixaban doses of $5 \mathrm{mg}$ or $10 \mathrm{mg}$ twice daily, reduce the dose by $50 \%$ when apixaban is coadministered with drugs that are strong dual inhibitors of CYP3A4 and P-glycoprotein (e.g., ketoconazole, itraconazole, ritonavir, and clarithromycin): if patient is already taking $25 \mathrm{mg}$ twice daily, avoid coadministration of apixaban with strong dual inhibitors of CYP3A4 and P-glycoprotein.

${ }^{b}$ For patients with severe renal impairment (CrCl $\geq 15$ to $<30 \mathrm{ml} / \mathrm{mm}$ ) or for patients receiving or starting concomitant $P$-glycoprotein inhibitors, the recommended dose of betrixaban is an initial single dose of $80 \mathrm{mg}$, followed by $40 \mathrm{mg}$ once daily.

${ }^{c}$ For patients who are taking certain concomitant P-glycoprotein inhibitors (verapamil, quinidine, azithromycin, clarithromycin, erythromycin, oral itraconazole, and oral ketoconazole), the recommended dose of edoxaban is 30 mg once daily.

${ }^{d}$ For patients with $\mathrm{CrCl}<30 \mathrm{ml} / \mathrm{min}$ and concomitant use of P-glycoprotein and strong CYP3A4 inhibitors or inducers, avoid coadministration with rivaroxaban.

${ }^{e}$ For patients with $\mathrm{CrCl}<50 \mathrm{ml}$ with concomitant use of P-glycoprotein inhibitors, avoid coadministration with dabigatran 
across Europe (Agnelli et al., 2015). Recently, a populationbased observational study, using health care data from Canada and the United States, found that the risk of major bleeding and all-cause mortality was not increased with NOAC use compared with warfarin for VTE (Jun et al., 2017). Data from these registry studies will help us better understand variation in real-world treatment of VTE and assess its effect on clinical and economic outcomes.

\section{Venous thromboembolism patient management with non-vitamin $\mathrm{K}$ oral anticoagulants}

Venous thromboembolism should be managed with anticoagulation therapy based on risk stratification, patient compliance, and cost. Current American College of Chest Physicians (ACCP) guidelines recommend apixaban, dabigatran, edoxaban, or rivaroxaban over VKA for the first 3 months in patients with DVT or PE and no cancer (Kearon et al., 2016) (betrixaban was approved for VTE prophylaxis in adult patients with acute illness after the issuance of these guidelines) (Portola Pharmaceuticals Inc, 2017). For patients treated with dabigatran or edoxaban, initial parenteral anticoagulation is given for 5-10 days before initiation. LMWH is recommended over NOACs or VKAs for the first 3 months for patients with DVT of the leg or PE and cancer. Patients are advised to continue on the same anticoagulant for extended therapy unless preferences or circumstances change for the patient (Kearon et al., 2016). The duration of optimal anticoagulation for preventing VTE recurrence is still debatable. At present, no data exist for therapy extending beyond 2 years (Piovella \& Iosub, 2017); such therapy should be individualized for each patient after an assessment of benefit versus risk of bleeding. A decision to end therapy should be based on a formal risk assessment and patient preference.

While advising and prescribing NOACs to patients, it is important to identify populations that may be difficult to manage as well as those that may benefit. Patients who are elderly or present with diabetes, heart failure, renal impairment, and/or had experienced a previous stroke or ischemic attack can complicate the management of VTE (Robinson, 2015). NOACs are not recommended for patients with mechanical valves or severe valvular disease and are contraindicated for patients with moderateto-severe hepatic impairment (Bentz, 2015). In addition, patients with clotting disorders or who present with abnormal clotting test results should consult a hematologist before starting anticoagulation therapy (Sumnig et al., 2014).

Patients being treated with VKAs who may be considered for NOAC therapy include those taking medications that interact with VKAs, those who have a poorly controlled INR on VKA, or those who have a history of a previous thromboembolic event on VKA. Patient convenience, such as geographic location to provider office, lifestyle choices including diet, and costs should also be considered when choosing between an NOAC and VKA (Robinson, 2015). Selecting an appropriate NOAC agent for eligible patients is challenging in the absence of direct comparative trials. However, considering agent pharmacokinetics, metabolism, and adverse effects can assist in the decision-making process (Millar \& Laffan, 2017).

Although NOACs do not require routine coagulation monitoring, regular contact with health care providers is needed to ensure safe and effective management of anticoagulation therapy. Regularly scheduled visits provide an opportunity for ongoing risk assessments and to address issues with compliance or adherence, adverse effects, alterations in renal or liver function, and signs of bleeding or thromboembolic events, which may require switching to an alternative anticoagulant. Drug-drug interactions as a result of concurrent medications should be considered alongside the duration of interaction exposure and risk of bleeding in a patient-specific manner. Concurrent use of NOACs with common medications, such as nonsteroidal anti-inflammatory agents (NSAIDs) or aspirin, can be associated with a higher risk of bleeding. Clinicians are advised to closely follow the product label regarding dose adjustments or discontinuation wherever necessary, unless the potential benefit justifies the increased risk of bleeding (Burnett et al., 2016). Substitution with acetaminophen, which does not have an antiplatelet effect, may be considered (Douketis, Bell, Eikelboom, \& Liew, 2014). Continued patient education is also imperative and can be conducted through leaflets and brochures complemented with face-to-face educational sessions to answer patients' questions regarding practical issues that can affect their everyday life (Robinson, 2015). Although the frequency of follow-up visits depends on a number of factors, patient visits should begin when transitioning from a parenteral anticoagulant to dabigatran or edoxaban or when changing doses of apixaban (after 7 days) or rivaroxaban (after 21 days) (Heidbuchel et al., 2015). After this transition, follow-up visits should occur every 3-6 months. Because all NOACs are to some extent excreted by the kidneys, kidney function and periodic creatinine clearance $(\mathrm{CrCl})$ level evaluation should be completed, as well as complete blood counts to check for anemia and thrombocytopenia (Robinson, 2015).

Appropriate periprocedural management of NOAC therapy is also important as $\sim 10 \%$ of patients on longterm anticoagulation require surgery (Raval et al., 2017). To dissipate the anticoagulation effect before surgery, the current labeling for each NOAC recommends discontinuation 24-48 hours for apixaban (Bristol-Myers Squibb Company, 2012), $1-2$ days ( $\mathrm{CrCl} \geq 50 \mathrm{ml} / \mathrm{min}$ ) or 3-5 days $(\mathrm{CrCl}<50 \mathrm{ml} / \mathrm{min}$ ) for dabigatran (Boehringer Ingelheim Pharmaceuticals, 2010), and at least 24 hours for edoxaban (Daiichi Sankyo Inc, 2015) or rivaroxaban (Janssen 
Pharmaceuticals Inc, 2011). NOAC therapy should resume once adequate hemostasis has been established after the surgical procedure. Pre- or postprocedural bridging with heparin is not required in patients with low thromboembolic risk (Raval et al., 2017). However, a parenteral anticoagulant should be considered if an NOAC cannot be orally administered after surgery.

\section{Management of bleeding and reversal of anticoagulant effect}

Current literature indicates that the primary consideration for continued anticoagulation should balance the risk of bleeding versus the risk of VTE recurrence for each individual patient (Joseph \& Bartholomew, 2016). Major bleeding in patients receiving a VKA is usually managed with a reversal agent that increases vitamin $\mathrm{K}$-dependent coagulation factors, such as fresh frozen plasma or factor concentrates (Ruff, Giugliano, \& Antman, 2016). Although major bleeding is higher with VKAs than with NOACs, lifethreatening bleeding can occur with NOACs, necessitating anticoagulant reversal. A specific antidote to dabigatran, idarucizumab, has been approved by the US Food and Drug Administration (FDA) and European Medicines Agency (EMA). Idarucizumab reverses the anticoagulation effects of dabigatran, acting immediately when given as two consecutive bolus intravenous injections no more than 15 minutes apart (Pollack Jr et al., 2015). However, there are currently no specific reversal agents approved for apixaban, betrixaban, edoxaban, or rivaroxaban (Ruff et al., 2016). A factor Xa inhibitor antidote, andexanet alfa, is currently under investigation in clinical trials.

Andexanet alfa is a recombinant modified human factor Xa decoy protein that binds to factor Xa inhibitors to counteract the anticoagulant effect. Also in development is ciraparantag, a universal antidote intended to reverse the effects of unfractionated heparin and LMWH in addition to all NOACs. Ciraparantag is a synthetic cationic molecule that binds to anticoagulants through noncovalent hydrogen bonding and charge-charge interactions; however, the exact mechanism is not fully known. Of note, NOACs have a much shorter half-life than VKAs, so non-life-threatening bleeding can often be more easily controlled once the drug has been eliminated. Current options for NOAC management of lifethreatening bleeding include supportive measures, repletion of clotting factors (e.g., prothrombin complex concentrates, activated prothrombin complex concentrates, or recombinant factor VIIa), blood transfusion, or surgery to repair the source of bleeding (Ruff et al., 2016).

\section{Reimagining traditional anticoagulation clinics}

There are more than 3,000 anticoagulation clinics (ACS) in the US that treat millions of Americans on anticoagulant therapy (Barnes, Nallamothu, Sales, \& Froehlich, 2016). Historically, ACs were designed to address the challenges with VKA treatment and provide organized, systematic management for anticoagulation therapy. Typically run by nurses, pharmacists, NPs, or physician assistants, the services provided by ACs include educational programs for patients, verifying clinical indications, reviewing laboratory tests and anticoagulation regimens involved in treatment, assessing pharmacologic interactions, and supervising patients undergoing surgery to reduce harm and risks often associated with periprocedural periods (Testa et al., 2012).

Assessment of the global anticoagulant market from 2008 to 2014 demonstrated the declining use of warfarin from $87.5 \%$ to $72 \%$, as more providers prescribe NOACs. Comparing direct thrombin inhibitors versus factor $\mathrm{Xa}$ inhibitors revealed a 1.35-fold increase in factor Xa inhibitor usage in 2014, with a preference for rivaroxaban (Oktay, 2015). This calls for expanding the traditional role of ACs to integrate patients with VTE on NOAC therapy. Anticoagulation clinics provide several advantages over traditional physician-managed practices, including managing patient anticoagulant therapy in one central location, skilled personnel to assist in clinical decisionmaking of anticoagulant dosage depending on personal characteristics and comorbidities, monitoring potential interactions with comedications, minimizing bleeding complications, and encouraging adherence (Barnes et al., 2016; Sylvester et al., 2017).

Although reimagined ACs would provide invaluable services, financing remains the largest barrier to this transition. Considering the lower risk of thrombosis and bleeding complications and no need for routine INR monitoring with NOACs, many health care systems and insurers may not see the financial value of NOAC management within these specialized clinics. As more patients are treated with NOACs, it will become imperative to adapt the services provided by ACs to decrease the number of adverse events related to NOACS and to support the financial investment (Barnes et al., 2016).

\section{Conclusions}

Non-vitamin K oral anticoagulants provide simpler, convenient, and safe management regimens for most patients with VTE. Rapid expansion of available therapeutic options requires NPs and pharmacists to build on their current expertise. The nursing profession has an excellent track record for adapting to paradigm shifts and for working together with pharmacists to achieve optimal outcomes for patients with VTE. Reimagined ACs catering to patients on NOACs as well as patients on VKAs further complement the intricacies of anticoagulation therapy and ensure consistent emphasis on patient history, education, and compliance. In summary, NOACs are increasingly being used to manage multiple thromboembolic diseases, including VTE, and enlisting the skills and knowledge of NPs and 
pharmacists will lead to optimal care and effective management for patients.

Acknowledgments: The authors thank Holly C. Cappelli, PhD, ProEd Communications, Inc., for her medical editorial assistance with this manuscript.

Authors' contributions: M. Schmerge, S. Earl, and C. Kline contributed to the conception and design of the work, interpretation of the content, critically revised the manuscript, and approved the final version to be published.

\section{Competing interests: $M$. Schmerge: Is a promotional} speaker for Janssen (Xarelto). S. Earl: Is a promotional speaker for Janssen (Xarelto). The remaning author reports no conflicts of interest.

Funding: Financial support for medical editorial assistance was provided by Janssen Pharmaceuticals, Inc.

\section{References}

Agnelli, G., Buller, H. R., Cohen, A., Curto, M., Gallus, A. S., Johnson, M., ... Raskob, G. E. (2013). Oral apixaban for the treatment of acute venous thromboembolism. N Eng J Med, 369, 799-808.

Agnelli, G., Buller, H. R., Cohen, A., Curto, M., Gallus, A. S., Johnson, M., ... Weitz, J. I. (2013). Apixaban for extended treatment of venous thromboembolism. N Eng J Medicine, 368, 699-708.

Agnelli, G., Gitt, A. K., Bauersachs, R., Fronk, E. M., Laeis, P., Mismetti, P., ... Prefer in VTE Investigators. (2015). The management of acute venous thromboembolism in clinical practice-study rationale and protocol of the European PREFER in VTE Registry. Thromb J, 13, 41.

Ashjian, E., Kurtz, B., Renner, E., Yeshe, R., \& Barnes, G. D. (2017). Evaluation of a pharmacist-led outpatient direct oral anticoagulant service. Am J Health-Syst Pharm, 74, 483-489.

Barnes, G. D., Nallamothu, B. K., Sales, A. E., \& Froehlich, J. B. (2016). Reimagining anticoagulation clinics in the era of direct oral anticoagulants. Circ Cardiovasc Qual Outcomes, 9, 182-185.

Bentz, B. A. (2015). Nonvitamin K antagonist oral anticoagulants in everyday practice: Stroke prevention in atrial fibrillation and treatment of venous thromboembolism. J Am Assoc Nurse Pract, 27, 721-731.

Boehringer Ingelheim Pharmaceuticals. (2010). Pradaxa (dabigatran etexilate mesylate) [package insert]. Retrieved from https://www. accessdata.fda.gov/drugsatfda_docs/label/2011/022512s007lbl. pdf.

Brahmandam, A., Abougergi, M. S., \& Chaar Ochoa, C. I. (2017). National trends in hospitalizations for venous thromboembolism. J Vasc Surg Venous Lymphat Disord, 5, 621-629 e622.

Bristol-Myers Squibb Company. (2012). Eliquis (apixaban) [package insert]. Retrieved from https://www.accessdata.fda.gov/drugsatfda_docs/label/2012/202155s000lbl.pdf.

Burnett, A. E., Mahan, C. E., Vazquez, S. R., Oertel, L. B., Garcia, D. A., \& Ansell, J. (2016). Guidance for the practical management of the direct oral anticoagulants (DOACS) in VTE treatment. J Thromb Thrombolysis, 41, 206-232.

Cohen, A., Hamilton, M., Mitchell, S., Phatak, H., Liu, X., Bird, A., ... Batson, S. (2015). Comparison of the novel oral anticoagulants apixaban, dabigatran, edoxaban, and rivaroxaban in the initial and longterm treatment and prevention of venous thromboembolism: Systematic review and network meta-analysis. PLoS One, 10, e0144856.

Cohen, A. T., Harrington, R. A., Goldhaber, S. Z., Hull, R. D., Wiens, B. L., Gold, A., ... Apex Investigators. (2016). Extended thromboprophylaxis with betrixaban in acutely ill medical patients. $N$ Eng J Med, $375,534-544$
Daiichi Sankyo Inc. (2015). Savaysa (edoxaban) [package insert]. Retrieved from https://www.accessdata.fda.gov/drugsatfda_docs/ label/2015/206316lbl.pdf.

Douketis, J., Bell, A. D., Eikelboom, J., \& Liew, A. (2014). Approach to the new oral anticoagulants in family practice: Part 2:

Addressing frequently asked questions. Can Fam Physician, 60, 997-1001.

Eijgenraam, P., ten Cate, H., \& ten Cate-Hoek, A. J. (2014). Practice of bridging anticoagulation: Guideline adherence and risk factors for bleeding. Neth J Med, 72, 157-164.

Einstein Investigators. (2010). Oral rivaroxaban for symptomatic venous thromboembolism. N Eng J Med, 2010, 2499-2510.

Einstein-PE Investigators. (2012). Oral rivaroxaban for the treatment of symptomatic pulmonary embolism. N Eng J Med, 2012, 1287-1297.

Goldstein, L. H., Sabag, P., Melykovsky, R., Hemi, S., Ron-Avraham, G., Azriel, M., ... Saliba, W. (2016). Could a coagulation nurse liaison improve compliance with venous thromboembolism prophylaxis in medical patients? J Nurs Care Qual, 31, E11-E15.

Heidbuchel, H., Berti, D., Campos, M., Desteghe, L., Freixo, A. P., Nunes, A. R., ... Lassila, R. (2015). Implementation of non-vitamin K antagonist oral anticoagulants in daily practice: The need for comprehensive education for professionals and patients. Thromb J, 13, 22.

Heit, J. A., Spencer, F. A., \& White, R. H. (2016). The epidemiology of venous thromboembolism. J Thromb Thrombolysis, 41, 3-14.

Hokusai-VTE Investigators. (2013). Edoxaban versus warfarin for the treatment of symptomatic venous thromboembolism. N Eng J Med, 2013, 1406-1415.

Hou, K., Yang, H., Ye, Z., Wang, Y., Liu, L., \& Cui, X. (2017). Effectiveness of pharmacist-led anticoagulation management on clinical outcomes: A systematic review and meta-analysis. J Pharm Pharm Sci, 20, 378-396.

Janssen Pharmaceuticals Inc. (2011). Xarelto (rivaroxaban) [package insert]. Retrieved from https://www.accessdata.fda.gov/drugsatfda_docs/label/2011/202439s001lbl.pdf.

Joseph, L., \& Bartholomew, J. R. (2016). Managing extended oral anticoagulation after unprovoked venous thromboembolism. J Cardiovasc Pharmacol Ther, 22, 28-39.

Jun, M., Lix, L. M., Durand, M., Dahl, M., Paterson, J. M., Dormuth, C. R., ... Canadian Network for Observational Drug Effect Studies, I. (2017). Comparative safety of direct oral anticoagulants and warfarin in venous thromboembolism: Multicentre, population based, observational study. BMJ, 359, j4323.

Kearon, C., Akl, E. A., Comerota, A. J., Prandoni, P., Bounameaux, H., Goldhaber, S. Z., ... American College of Chest Physicians. (2012). Antithrombotic therapy for VTE disease: Antithrombotic therapy and prevention of thrombosis, 9th ed: American College of Chest Physicians evidence-based clinical practice guidelines. Chest, 141 (2 suppl), e419S-494S.

Kearon, C., Akl, E. A., Ornelas, J., Blaivas, A., Jimenez, D., Bounameaux, H., ... Moores, L. (2016). Antithrombotic therapy for VTE disease: CHEST guideline and expert panel report. Chest, 149, 315-352.

Keller, L., Marten, S., Hecker, J., Werth, S., Tittl, L., \& Beyer-Westendorf, J. (2016). Treatment of acute VTE with rivaroxaban-results of the prospective Dresden NOAC Registry (NCT01588119). Presented at: ASH 58th Annual Meeting and Exposition, December 3-6, 2016, San Diego, CA.

Lee, L. H. (2016). DOACs-advances and limitations in real world. Thromb J, 14(suppl 1), 17.

Lockwood, R., Kable, A., \& Hunter, S. (2017). Evaluation of a nurse-led intervention to improve adherence to recommended guidelines for prevention of venous thromboembolism for hip and knee arthroplasty patients: A quasi-experimental study. J Clin Nurs. doi: 10.1111/jocn.14141. [Epub ahead of print].

Marcum, Z. A., Bellon, J. E., Li, J., Gellad, W. F., \& Donohue, J. M. (2016). New chronic disease medication prescribing by nurse practitioners, physician assistants, and primary care physicians: A cohort study. BMC Health Services Research, 16, 312.

Millar, C. M., \& Laffan, M. A. (2017). Drug therapy in anticoagulation: Which drug for which patient? Clin Med (Lond), 17, 233-244.

Mozaffarian, D., Benjamin, E. J., Go, A. S., Arnett, D. K., Blaha, M. J., Cushman, M., ... Stroke Statistics Subcommittee. (2016). Heart disease and stroke statistics-2016 update: A report from the American Heart Association. Circulation, 133, e38-360. 
Oktay, E. (2015). Will NOACs become the new standard of care in anticoagulation therapy? Int I Cardiovasc Acad, 1, 1-4.

Palladino, M., Merli, G., \& Thomson, L. (2013). Evaluation of the oral direct factor Xa inhibitor-betrixaban. Expert Opin Investig Drugs, 22, 1465-1472.

Piovella, F., \& Iosub, D. I. (2017). Extended non-vitamin K antagonist oral anticoagulation therapy for prevention of recurrent venous thromboembolism. Thromb Res, 152, 87-92.

Pollack, C. V., Jr., Reilly, P. A., Eikelboom, J., Glund, S., Verhamme, P., Bernstein, R. A., ... Kamphuisen, P. W. (2015). Idarucizumab for dabigatran reversal. N Eng J Med, 373, 511-520.

Portola Pharmaceuticals Inc. (2017). Bevyxxa (betrixaban) [package insert]. Retrived from https://www.accessdata.fda.gov/drugsatfda_docs/label/2017/208383s000lbl.pdf.

Raschi, E., Bianchin, M., Ageno, W., De Ponti, R., \& De Ponti, F. (2016). Risk-benefit profile of direct-acting oral anticoagulants in established therapeutic indications: An overview of systematic reviews and observational studies. Drug Safety, 39, 1175-1187.

Raval, A. N., Cigarroa, J. E., Chung, M. K., Diaz-Sandoval, L. J., Diercks, D., Piccini, J. P., ... Council on Quality of Care and Outcomes Research. (2017). Management of patients on non-vitamin K antagonist oral anticoagulants in the acute care and periprocedural setting: A scientific statement from the American Heart Association. Circulation, 135, e604-e633.

Robinson, M. (2015). Non-vitamin K antagonist oral anticoagulants: Redefining the role of the nurse to improve patient care. Open J Nurs, 5, 1142-1157.

Ruff, C. T., Giugliano, R. P., \& Antman, E. M. (2016). Management of bleeding with non-vitamin $\mathrm{K}$ antagonist oral anticoagulants in the era of specific reversal agents. Circulation, 134, 248-261.

Schein, J. R., White, C. M., Nelson, W. W., Kluger, J., Mearns, E. S., \& Coleman, C. I. (2016). Vitamin K antagonist use: Evidence of the difficulty of achieving and maintaining target INR range and subsequent consequences. Thromb J, 14, 14.

Schulman, S., Kakkar, A. K., Goldhaber, S. Z., Schellong, S., Eriksson, H., Mismetti, P., ... Peter, N. (2014). Treatment of acute venous thromboembolism with dabigatran or warfarin and pooled analysis. Circulation, 129, 764-772.

Schulman, S., Kearon, C., Kakkar, A. K., Mismetti, P., Schellong, S., Eriksson, H., ... Goldhaber, S. Z. (2009). Dabigatran versus warfarin in the treatment of acute venous thromboembolism. N Eng J Med, 361 , 2342-2352.

Schulman, S., Kearon, C., Kakkar, A. K., Schellong, S., Eriksson, H., Baanstra, D., ... Goldhaber, S. Z. (2013). Extended use of dabigatran, warfarin, or placebo in venous thromboembolism. N Eng J Medicine, 368, 709-718.

Spyropoulos, A. C., Preblick, R., Kwong, J., Lingohr-Smith, M., \& Lin, J. (2015). Is adherence to the American College of Chest Physicians recommended anticoagulation treatment duration associated with different outcomes among patients with venous thromboembolism? Blood, 126, 1126.

Sumnig, A., Grotevendt, A., Westphal, A., Fiene, M., Greinacher, A., \& Thiele, T. (2014). Acquired hemophilia with inhibitors presenting as an emergency: Misinterpretation of clotting results during direct oral anticoagulation. Dtsch Arztebl Int, 111, 345-348.

Sylvester, K. W., Ting, C., Lewin, A., Collins, P., Fanikos, J., Goldhaber, S. Z., et al. (2018). Expanding anticoagulation management services to include direct oral anticoagulants. J Thromb Thrombolysis, 45, 274-280.

Testa, S., Paoletti, O., Zimmermann, A., Bassi, L., Zambelli, S., \& Cancellieri, E. (2012). The role of anticoagulation clinics in the era of new oral anticoagulants. Thrombosis, 2012, 835356.

Turpie, A. G., Mantovani, L. G., Haas, S., Kreutz, R., Monje, D., Schneider, J., ... Ageno, W. (2015). Xalia, a non-interventional study comparing rivaroxaban with standard anticoagulation for initial and long-term therapy in deep vein thrombosis. Blood, 126, 894.

Weitz, J. I., Haas, S., Ageno, W., Angchaisuksiri, P., Bounameaux, H., Nielsen, J. D., ... Kakkar, A. K. (2016). Global anticoagulant registry in the field-venous thromboembolism (GARFIELD-VTE). Rationale and design. Thromb Haemost, 116, 1172-1179. 